\title{
Genomic and stem cell policy issues: more alike than different?
}

\author{
Mary A Majumder*
}

In a comparison of policy issues related to genomics and stem cells, initially, the differences seem to occupy the foreground. After all, no one is seeking to criminalize the conduct of genomic research, whereas researchers working with human embryonic stem cells face the prospect of criminal penalties in certain jurisdictions. And, in the USA, a polarized political climate, and twists and turns in litigation centering on a statutory provision that prohibits federal funding of 'research in which a human embryo or embryos are destroyed' [1], have heightened a sense of insecurity in the stem cell field [2]. However, stem cell policy concerns have always extended beyond the embryo. Furthermore, with the expansion of work using human induced pluripotent stem cells, created without embryo destruction, it is becoming increasingly likely that policy discussion around stem cells and genomics will converge in significant respects. I would suggest that five areas of concern are salient to both fields: (1) communication, (2) consent, (3) consultation, (4) commercialization, and (5) clinical integration.

\section{Communication}

Significant sums of public money have been and are being invested in genomic and stem cell research. Perhaps most attention-grabbing in the USA have been the Human Genome Project and the California Stem Cell Research and Cures Initiative (10 years of funding, approved by ballot in 2004), each with a price tag of approximately $\$ 3$ billion. Given a perception that members of the public are motivated less by a thirst for fundamental knowledge than a desire for cures for diseases, enthusiasts have not always been modest in their assessments of the scope or speed of progress to be expected on the clinical front [3]. Yet this communication strategy, successful in building public support in the short term, has the potential to backfire down the road. For example, in California, what will happen in 2014, or

*Correspondence: majumder@bcm.edu

Center for Medical Ethics and Health Policy, Baylor College of Medicine, One Baylor Plaza, Houston, TX 77030, USA
2017 (granting an additional 3 years for time lost to legal battles), if patients with paralysis have yet to walk and patients with diabetes are still going blind? Tempering enthusiasm with caution could help to avoid boom-andbust cycles in which public generosity gives way to disappointment and loss of funding. Still, there is a difference between resisting pressure to exaggerate the ease of finding cures and dampening down all excitement about the clinical potential of dramatic advances in basic science. The task is to find a way of harnessing public hopes and support for investment in scientific research to achieve realistic longer-term goals for improvement in clinical care and outcomes.

\section{Consent}

How much time and effort have policy bodies and institutional review boards invested in specifying conditions for informed consent for research uses of human biological material and personal information? I have not seen a calculation, but it seems likely that the investment has been substantial. So it is interesting and perhaps also disheartening that consensus on consent has proven elusive. A recent review article focusing on genetics and genomics presents five competing options for informed consent for research uses of biological material and information: deference to local review board determinations; categorical consent (that is, permitting donors to impose restrictions); blanket consent; opt-out; and no consent beyond any authorization related to initial collection [4]. Consensus has been difficult to achieve, in part because the risks of participation are somewhat intangible. The chance that even 'de-identified' information might be linked to an individual by third parties, and this could lead to discrimination or other harm, or the possibility that a person's DNA or data could end up contributing to research to which he or she objects, may seem insignificant to some. Yet such matters matter - scandals have arisen and biorepositories have been destroyed due to the efforts of individuals surprised to learn that they or their loved ones have been unwitting subjects of research. A literature is now developing around consent for stem cell research that cites concerns about respect for persons and privacy that are similar to concerns related to 
genomics [5,6], as well as special issues related to oocyte and embryo donation (for example, treatment of third party gamete donors) [7].

\section{Consultation}

There is a growing emphasis internationally on consultation with those most affected and the public at large across many areas of science. The sorts of activities used for consultation are diverse, ranging from traditional surveys, opinion polling and focus groups to citizen consensus conferences, 'deliberative polling' and other forms of dialogical, substantive public engagement. Furthermore, the purposes of such consultation fall within a spectrum from placating interest groups or crafting more effective means of marketing science to giving citizens a more direct role in guiding public investment in science or enlisting them in the 'upstream' planning and policy setting for major research initiatives. In human genomics, consultation efforts have been linked to the creation of population-based biobanks or databases, while in the stem cell field, topics for dialogue have included oocyte and embryo donation and the creation of human-non-human animal chimeras. Stem-cell derived gametes may soon be added to the agendas of such consultations, especially given the potential for combination with techniques for genetic modification [8].

\section{Commercialization}

In a recent statement on data and materials sharing and intellectual property in stem cell science, the Hinxton Group provides a useful summary of concerns at the intersection of science and commerce [9]. Consider patents. Restrictions on liberty via policies that allow for patenting inventions are often justified with reference to the incentives that patents create for innovation. In recent years some have argued that patents and proprietary tendencies may actually be hampering innovation, as well as creating financial barriers to access when inventions finally make it to market (whether high prices reflect the producer's exploitation of its own patents through monopoly pricing or the producer's need to pay significant royalties to other patent holders). To address these concerns, the Hinxton Group proposes a number of remedial steps, including: a global resource to facilitate access to registry information; a central hub for patent information; exploration of options for collective management of intellectual property, including patent pools and a norm of non-exclusive licensing; and reassessment of current standards for granting patents. Similar issues have arisen in the context of genomics [10], and the Hinxton Group urges emulation of models that have emerged there, for example, resources for sharing of DNA sequence information.

\section{Clinical integration}

One of the next policy frontiers is surely clinical integration of the results of basic and translational research in the two fields. Given the current fiscal crises at all levels of government, and the potential for steep pricing, it seems likely that considerable energy in the future will be directed to determining whether better diagnostics or cures can be achieved within a sustainable system of health care. Ideally, the discussion will center on costeffectiveness (which interventions deliver good value for money) and equity (can we assure that benefits reach those with the greatest need). It is entirely possible that policy will instead be driven by cost alone and that benefits will be concentrated among those already advantaged - unless consultation moves policy in the direction of fairness.

If these areas of concern are indeed common, there is the potential for mutual learning, and to the extent sensible and feasible, harmonization of the policies that shape both fields.

\section{Competing interests}

The author declares that she has no competing interests.

\section{Acknowledgements}

I thank Cynthia Cohen and Amy McGuire for their critical reading and helpful suggestions.

Published: 7 June 2011

\section{References}

1. Omnibus Appropriations Act 2009, Pub. L. No. 111-118, § 509(a)(2), 123 Stat. $524,803$.

2. Levine AD: Policy uncertainty and the conduct of stem cell research. Cell Stem Cell 2011, 8:132-135

3. Adams A: Stem cell cures? The long and winding road. Stanford Medicine Magazine Spring 2007 [http://stanmed.stanford.edu/2007spring/stem.html]

4. McGuire AL, Beskow LM: Informed consent in genomics and genetic research. Annu Rev Genomics Hum Genet 2010, 11:361-381.

5. Knoppers BM, Isasi R, Benvenisty N, Kim OJ, Lomax G, Morris C, Murray TH, Lee EH, Perry M, Richardson G, Sipp D, Tanner K, Wahlström J, de Wert G, Zeng F: Publishing SNP genotypes of human embryonic stem cell lines: policy statement of the International Stem Cell Forum Ethics Working Party. Stem Cell Rev 2011. doi: 10.1007/s12015-010-9226-2.

6. Aalto-Setälä, Conklin BR, Lo B: Obtaining consent for future research with induced pluripotent cells: opportunities and challenges. PLOS Biol 2009, 7:204-208.

7. Lo B, Parham L, Cedars M, Fisher S, Gates E, Giudice L, Halme DG, Hershon W, Kriegstein A, Rao R, Roberts C, Wagner R: Research ethics. NIH guidelines for stem cell research and gamete donors. Science 2010, 327:962-963.

8. Science, Ethics and Policy Challenges of Pluripotent Stem cell-derived Gametes. [http://www.hinxtongroup.org/au_pscdg_cs.html]

9. Policies and Practices Governing Data and Materials Sharing and Intellectual Property in Stem Cell Science. [http://hinxtongroup.wordpress. com/meeting-information-2/consensus_statement]

10. Cook-Deegan R, Heaney C: Patents in genomics and human genetics. Annu Rev Genomics Hum Genet 2010, 11:383-425.

doi:10.1186/gm251

Cite this article as: Majumder MA: Genomic and stem cell policy issues: more alike than different?. Genome Medicine 2011, 3:35. 